\title{
Spatio-temporal variations of b-value in and around north Pakistan
}

\author{
Khaista Rehman ${ }^{1, *}$, Asghar Ali ${ }^{2}$, Sajjad Ahmed ${ }^{2}$, Wajid Ali ${ }^{1}$, \\ Aamir $\mathrm{Ali}^{3}$ and Muhammad Younis $\mathrm{KHAN}^{1}$ \\ ${ }^{1}$ National Centre of Excellence in Geology, University of Peshawar, Khyber Pakhtunkhwa 25120, Pakistan. \\ ${ }^{2}$ Department of Geology, University of Peshawar, Khyber Pakhtunkhwa 25120, Pakistan. \\ ${ }^{3}$ Department of Earth Sciences, Quaid-i-Azam University, 45320, Islamabad, Pakistan. \\ ${ }^{*}$ Corresponding author.e-mail: rehmannceg@upesh.edu.pk
}

The seismotectonic structure of north Pakistan has been formed by ongoing collision between the Eurasian and Indian plates. North Pakistan and the adjoining areas experienced many large earthquakes in the past, which resulted in considerable damages and loss of life. A magnitude-homogenous earthquake catalogue for north Pakistan and its surrounding areas for the instrumental period from 1964 to 2007 is used for analysis. We presented seismicity picture of the Hindukush-Pamir-Karakoram (HPK), Kohistan Island Arc (KIA) and Hazara-Kashmir-Himalayas (HKH) using various histograms and time series plots of the dataset. The b-value for each accreted domain is derived separately and investigated through a process of mutual correlation. Our computed temporal variation of b-value in Hazara region shows a significant decrease prior to 2005 Kashmir earthquake.

\section{Introduction}

The youngest E-W trending Himalaya evolved in response to the collision of the Eurasian and Indian plates $\sim 50$ million years ago (Faisal et al. 2014). It stretches over $3000 \mathrm{~km}$ from Afghanistan in the west to Burma in the east and ranges in width from 250 to $350 \mathrm{~km}$ from south to north (Kearey and Vine 1990). The tectonic evolution of Himalaya in the Indian plate is of particular interest because of its seismic, structural and tectonic implications. The Late Cretaceous Kohistan Island arc separates the Indian plate from the Eurasian plate. It has the northern contact with the Karakoram along the Main Karakoram Thrust (MKT) and the southern contact with the Himalaya along the Main Mantle Thrust (MMT). Apart from Pakistan, the Indian plate has direct contact along the Indus-Tsangpo suture zone (ITSZ, $30-34.80^{\circ} \mathrm{N}$, $\left.75.20-94.40^{\circ} \mathrm{E}\right)$ with the Eurasian plate. Continued underthrusting of the Indian plate beneath the Eurasian plate along the ITSZ has thickened the crust up to $\sim 75 \mathrm{~km}$. South of the MMT, the Himalayan fold and thrust belt is characterized by the Khairabad-Panjal (KP), Main Boundary Thrust (MBT), Jhelum, Salt Range and Kalabagh faults and Hazara Kashmir and Nanga ParbatHaramosh syntaxes (figure 1). The KP and MBT are tightly folded with counterclockwise shear sense in the regional scale Hazara Kashmir Syntaxis (figure 1, Ali et al. 2015). The counterclockwise rotation of the Indian plate in the Hazara Kashmir Syntaxis is accommodated by the development of the sinistral Jhelum strike slip fault (Ali et al. 2015). The NNW dextral Kalabagh fault, which has been the epicenter of several earthquakes across the region displaces the Salt Range Thrust (SRT) (Kazmi 1979). The seismotectonic features

Keywords. Seismicity; b-value; spatio-temporal distribution; Pakistan. 


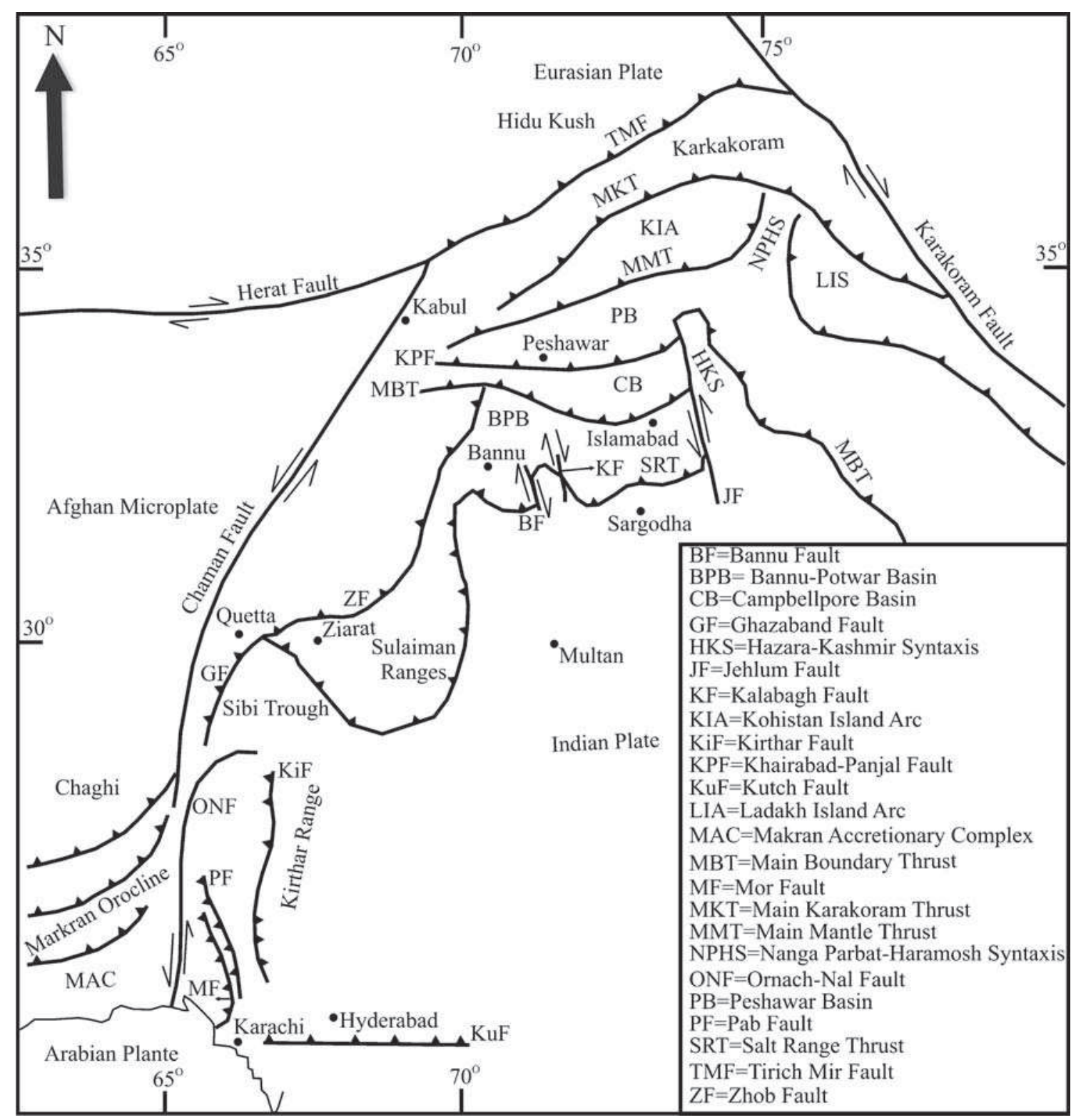

Figure 1. Regional tectonic map of north Pakistan and its adjoining areas showing locations of major faults (modified after Kazmi and Jan 1997).

of north Pakistan and adjoining areas have been based on geological data (e.g., Kazmi 1979; Kazmi and Jan 1997). For this reason, seismological methods are required to examine the seismicity of the region.

Documentation of historical and instrumental earthquake catalogues in and around Pakistan started from the mid-19th century up to the end of the 20th century. However, the quality and coverage of earthquake data in and around Pakistan improved in the early 1960s, after the establishment of World Wide Seismographic Stations Network (WWSSN) that comprised of about 120 stations in 60 countries. The data of small events before the establishment of WWSSN contains lack of accuracy, homogeneity and completeness in the dataset and these properties mainly depend on the sophistication of the instruments and networks used to record the earthquakes (Burton et al. 2004). The main objective of this study is to map the spatial and temporal variations of seismicity (b-value) in and around north Pakistan, using magnitude-homogeneous earthquake catalogue events after 1964 . This study isolates the earthquake data, based on nearly self-similar tectonics of different regions named as HindukushPamir-Karakoram (HPK), Kohistan Island Arc (KIA) and Hazara-Kashmir-Himalayas (HKH) in north Pakistan. The spatio-temporal variation of seismicity based on epicentral distribution and 


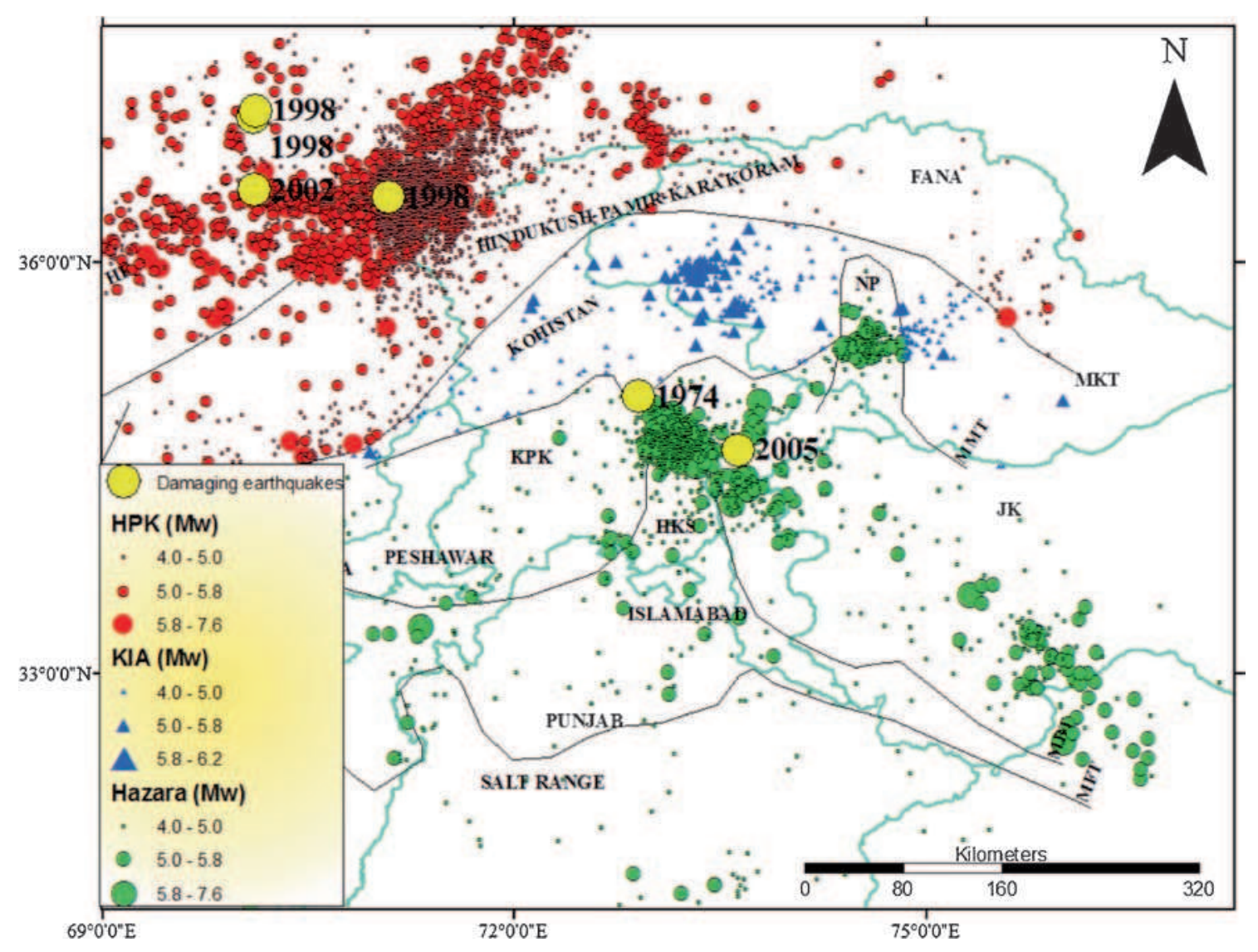

Figure 2. Distributions of earthquakes and tectonic faults in and around north Pakistan (HPK, KIA and HKH) that are named in the text. Abbreviations of places and fault names: KPK: Khyber Pakhtunkhwa; JK: Jammu and Kashmir; FATA: Federally Administrated Tribal Areas; FANA: Federally Administrated Northern Areas; MKT: Main Karakoram Fault; MMT: Main Mantle Thrust; MBT: Main Boundary Thrust; MFT: Main Frontal Thrust; NP: Nanga Parbat-Haramosh; HF: Herat Fault.

depth-section plots is separately analyzed for each region. The b-values are separately derived for the HPK, KIA, and HKH and the results are through mutual correlation for the three regions. Furthermore, this study explains the decrease in b-value prior to 2005 Kashmir earthquake using seismicity distributed in the HKH.

In this study, we used an alternative method for the estimation of b-values using advanced software package widely used among geoscientists called ZMAP (Wiemer 2001). ZMAP is an open-source software that has been previously used to estimate seismic hazards (Wiemer 2001; Spassov et al. 2002; Farrell et al. 2009). ZMAP contains many advanced seismological functions of earthquake catalogue analysis, measuring variations in b-values, time series analysis and declustering. Damanik et al. (2010) used ZMAP with a magnitude of completeness of around 4.7 for the greater region of Java island $\left(106-115.5^{\circ},-0.7\right.$ to $\left.-11.5^{\circ}\right)$ using earthquake catalogue data from the United States Geological Survey (USGS) and Engdahl catalogs.

\section{Seismicity and tectonic of north Pakistan and adjacent areas}

The northern Pakistan and the adjacent areas are characterized by continuous seismic activity and occurrence of moderate to large earthquakes (i.e., Mw 5.0-7.6). Damaging earthquakes in and around north Pakistan are highlighted in yellow circle with the year of their occurrence (figure 2). According to Khan (2003), Khan et al. (2010) and Faisal et al. (2014), north Pakistan and the adjoining areas are divided into HPK, KIA and HKH tectonic domains. This part of Pakistan consists of tectonically active Pamir, Hindukush, Karakoram and Himalayan mountain ranges. The HPK, KIA and Indian plates $(\mathrm{HKH})$ are episodically accreted from north to south from the Jurassic to Early Miocene. The accretion of the KIA, which formed as a result of intra-oceanic subduction in the Tethys during the Cretaceous, with the HPK along the MKT (Shyok Suture Zone) in the Later Cretaceous was followed by the Indian plate collision with the KIA along the MMT (Indus Suture Zone) in the Late Oligocene and Early 
Miocene (Faisal et al. 2014). The collision between the Indian plate and the KIA resulted into the formation of the Himalayan mountain belts. The Late Oligocene and Early Miocene tectonic deformation front along the MMT shifted southward with the initial of the KP between Miocene and Pliocene ( 20 Ma, Treloar et al. 1992). The continuous southward migration of the tectonic front within the Indian plate resulted into the formation of the Main Boundary Thrust in the Late Tertiary ( 10 Ma, Treloar et al. 1992). The KP and MBT are tightly folded by the Hazara Kashmir tectonic event within the Indian plate (Ali et al. 2015).

The above regional structures, which divide north Pakistan into three distinct tectonic domains, enabled to look into the seismicity of HPK, KIA and $\mathrm{HKH}$ (figure 2). This tectonic variation in and around Pakistan is reflected by seismicity (figure 2). According to the United States Geological Survey (USGS), two shallow-depth earthquakes (depth = $33 \mathrm{~km})$ of 4 February $1998(\mathrm{Mw}=6.1)$ and 30 May $1998(\mathrm{Mw}=6.6)$ and two intermediate-depth earthquakes of 2 February $1998(\mathrm{Mw}=5.4$, depth $=$ $236 \mathrm{~km})$ and 3 March $2002(\mathrm{Mw}=7.4$, depth $=$ $256 \mathrm{~km}$ ) occurred in the HPK region. The exposed part of the Hindukush in Afghanistan has been considered as the main source of earthquakes felt within Pakistan. On 28 December 1974, an earthquake of $\mathrm{Mw}=6.2$ along the MMT, which was felt over $300,000 \mathrm{~km}^{2}$ ruined completely the Pattan and Palas villages (Peiris et al. 2008). During that earthquake, 1000-1500 people (dead or injured) and 4000-6000 houses were damaged. The October 8, 2005 earthquake of $\mathrm{Mw}=7.6$ in the $\mathrm{HKH}$ along the MBT within the Hazara Kashmir Syntaxis killed over 70,000 people and severely damaged residential buildings, schools, bridges and hospitals (Burton et al. 2006). This clearly indicates a high seismicity zone confirmed by rich earthquake data including the dominant aftershocks of 2005 earthquake (Rehman et al. 2014).

\section{Data}

The spatio-temporal variation in seismicity is an important input for understanding seismo-tectonic environment and seismic hazard analysis. To study seismicity variation in a region, we need input in the form of an earthquake catalogue (Burton 1990). Instrumental earthquake data are the basis of the present study to interpret spatial-temporal seismicity variation of north Pakistan and its surrounding areas (Rehman et al. 2014). The earthquake catalogue for north Pakistan and adjoining areas drawn from Rehman et al. (2014) contain 5419 earthquakes during the time periods of 1964-2007. This catalogue is based upon earthquake data from the
International Seismological Centre (ISC); Engdahl catalogue (Engdahl et al. 1998); Global Seismic Hazard Assessment Programme (GSHAP; Zhang et al. 1999); Preliminary Determination of Epicentres (PDE); USGS/National Earthquake Information Centre (NEIC) and other data sources (Kondorskaya and Shebalin 1982; Rao and Rao 1984; Dunbar et al. 1992; Johnston 1994). Rehman et al. (2014) used magnitude-homogeneous earthquake catalogue for delineation of seismic clusters in and around Pakistan using K-means method. The earthquake catalogue was homogenized with respect to surface wave magnitude and moment magnitude. Duplicate events were recognized and removed algorithmically, and later verified by visual assessment. Scaling between magnitude scales was performed using Scordilis (2006) relations with homogenized moment magnitude $\mathrm{Mw} \geq 4.08$ for the current analysis.

\section{Data analysis}

Various statistical calculations of seismicity (like histogram creation and b-value) are incorporated in hazard zonation maps and used as a basis for seismic hazard assessment (Wiemer 2001; Spassov et al. 2002; Farrell et al. 2009). In most cases, the time series analysis of an earthquake catalogue and b-value calculations is an important factor for understanding seismicity. In the current study, the statistical calculations of time series and b-value analysis are performed using the ZMAP software package (Wiemer 2001).

\subsection{Time series analysis}

Time and magnitude histograms for the areas of HPK, KIA and HKH are shown in figure $3(\mathrm{a}-\mathrm{c})$. In figure 3(a), HPK appears to have been the first peak in earthquake activity during the time period 1982-1991. A second peak occurred between 1998 and 2006. Prior to the initial peak, and in between these two, there are less marked fluctuations in time. The frequency histogram for KIA (figure 3b) is more or less the complete opposite of the HPK. Three prominent peaks reveal at specific years (1974, 1982 and 2003) rather than intervals. There are quiescent dates (i.e., 1967, 1969, 1970, 1987 and 1989) observed in KIA. Inspecting figure 3(c) for $\mathrm{HKH}$, we detect sudden peak in the value of frequency histogram for the earthquake of October 8, 2005 and its aftershocks. Apart from the 2005 earthquake, the HKH is characterized by hundred earthquakes reported in 2003. The reported earthquakes from the remaining time periods reveal a cyclic pattern; with relative increase in number of new millennium earthquakes. Figure 3 shows that the best earthquake frequency histogram is that of the 

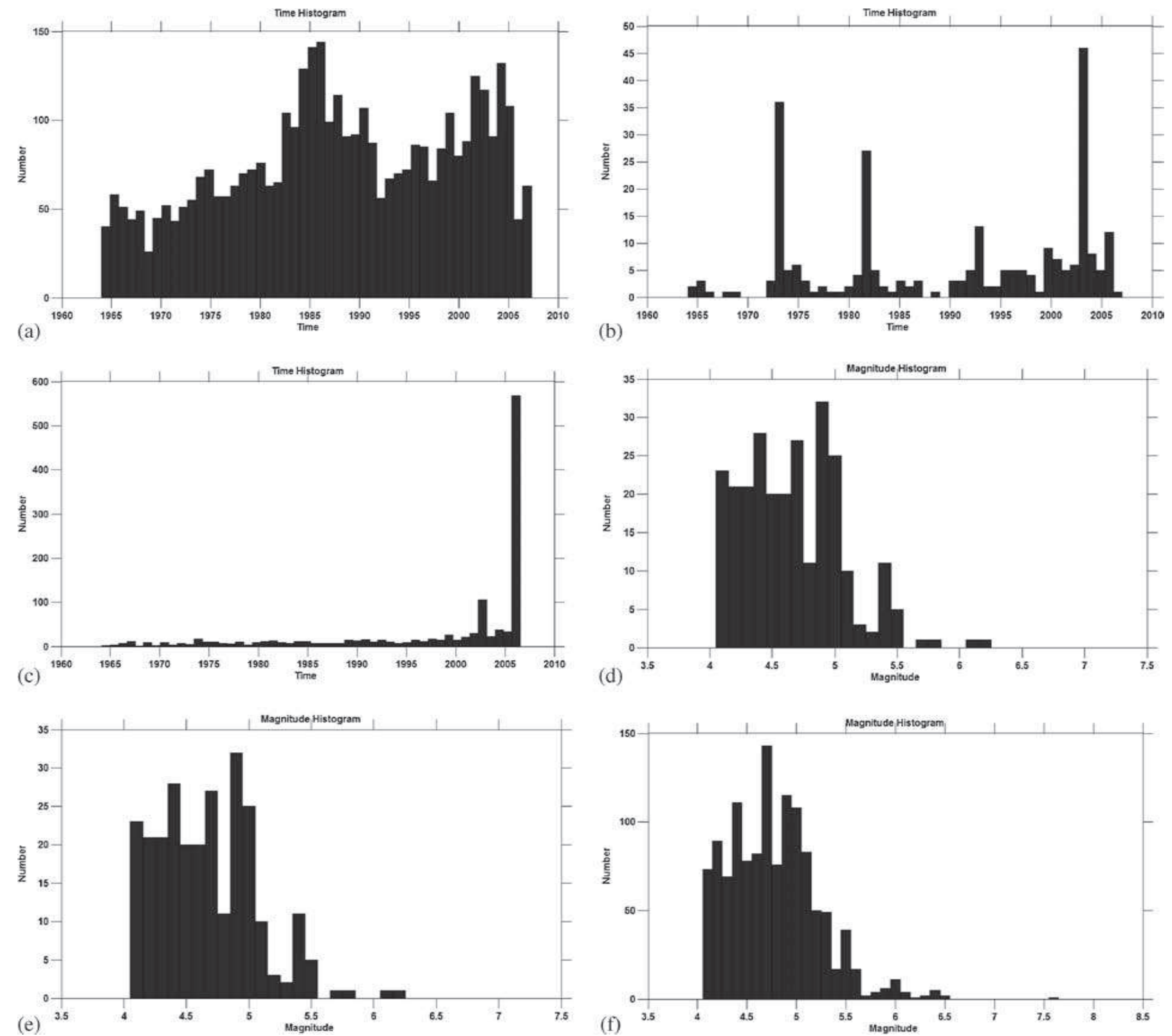
HPK because of the large number of instrumental earthquakes that exist for this region. Similarly, magnitude histograms indicate that earthquakes with magnitude range between 4.0 and 5.5 dominated the HPK tectonic domain (figure 3d). Figure 3(d) (HPK) suggests an organized pattern from magnitude 5.6 and above, with a gradual decrease of earthquakes having large magnitudes. Figure 3(e) (KIA) shows only four earthquakes (i.e., 5.69, 5.76, 6.1 and 6.22 ) after 5.55, while figure 3(f) (HKH) reflects variation in the magnitude ranges from 5.5 to 6.5 with a gap after 6.5 until 7.6 magnitude earthquake of 2005. Figure $4(\mathrm{a}-\mathrm{c})$ indicates magnitude $v s$. time plots of the HPK, KIA and HKH regions, respectively. Figure 4(a) shows that a large number of earthquakes ( $\mathrm{Mw} \leq 6.0)$ during 1964-2007 occurred in HPK compared to KIA (figure 4b) and HKH (figure 4c). Furthermore, continuous seismic activity can be seen $(\mathrm{Mw} \geq 6.0)$ in figure $4(\mathrm{a})$, against two earthquakes reported in the KIA (figure 4b) and five earthquakes in the $\mathrm{HKH}$ (figure 4c), excluding Kashmir earthquake aftershocks. Similarly, we divide the time series analysis of earthquakes depth (figure $4 \mathrm{~d}-\mathrm{f}$ ) into shallow $(<70 \mathrm{~km})$, intermediate $(70-170 \mathrm{~km})$ and deep $(>170 \mathrm{~km})$ focus earthquakes. In general, this figure shows quite different fashion of earthquakes in the HPK, KIA and HKH. The HPK zone (figure 4d) is very prominent with a large number of intermediate and deep focus earthquake clusters. Moreover, the shallow focus earthquakes are dominated in the KIA and HKH (figure 4e and $\mathrm{f}$ ). This information provides an appropriate data for mapping spatiotemporal distribution of b-value using ZMAP.

\subsection{The b-value}

The famous relationship of Gutenberg and Richter (1944) has been widely used in the field of earthquake seismology and seismic hazard studies. This seismic hazard, magnitude-frequency relationship defines the frequency of earthquake occurrence and magnitude in an area. The mathematical form of this relationship is given by

$$
\log N=a-b M,
$$

where $N$ is the cumulative number of earthquakes and $a$ and $b$ are the constants. $a$ denotes the general seismicity level in the area and $b$ denotes the slope of the line representing the seismotectonic level of the region. The analysis of seismicity using b-value has been studied in various parts of the world, for example, study of distribution of earthquakes in and around Tarbela Dam site, north Pakistan (Seeber et al. 1980), seismicity analysis of the northernmost part of Red Sea (1995-1999) (Korrat et al. 2006), temporal analysis of seismic b-values beneath northeastern Japan island arc
(Cao and Gao 2002) and mapping of b-values near Nicoya Peninsula, Costa Rica (Ghosh et al. 2008). These studies, among several other studies agree that low values of $b$ are found in the high seismotectonic regions and vice versa (Wyss 1973; Urbancic et al. 1992; Khan and Chakraborty 2007).

A number of geoscientists have calculated b-value using weighted least squares or with the method of maximum likelihood (Aki 1965; Bender 1983; Pacheco and Sykes 1992; Main 2000; Wiemer and Wyss 2002; Nuannin 2006; Damanik et al. 2010; Jafari 2013). Numerical and analytical study of Sandri and Marzocchi (2007) shows that the least square method contains bias due to the accumulation, logarithmic conversion and observational errors. In this study, we have used maximum likelihood method (Aki 1965; Wiemer and Wyss 2002) for the estimation of b-values (equation 2). The advantage of this method (equation 2) is that it reduces the biases of the b-value and its uncertainty (Marzocchi and Sandri 2003). A maximum likelihood estimate of b-value is given by:

$$
b=\log _{10} e\left(\frac{1}{\bar{M}-M_{\min }}\right),
$$

where $\bar{M}$ is the average magnitude and $M_{\min }$ is the minimum magnitude of the dataset. An estimate of the standard deviation $(\delta b)$ of the b-value is given by equation (3) as suggested by Shi and Bolt (1982):

$$
\delta b=2.3 b^{2} \sqrt{\frac{\sum_{i}^{N}\left(M_{i}-\bar{M}\right)^{2}}{n(n-1)}},
$$

where $n$ is the sample size (total number of events of the earthquake catalogue). Equation (4) is used to determine the probability that the two samples may draw from the same population (Utsu 1992) which explicitly accounts for the number of earthquakes in the sample sets:

$$
p \approx \exp \left(\frac{d A}{2}-2\right)
$$

where

$$
\begin{aligned}
d A= & -2 N \ln (N)+2 N_{1} \ln \left(N_{1}+N_{2} b_{1} / b_{2}\right) \\
& +2 N_{2} \ln \left(N_{1} b_{2} / b_{1}+N_{2}\right)-2
\end{aligned}
$$

and

$$
N=N_{1}+N_{2}
$$

\section{Discussions and conclusions}

The computed b-values for the HPK, KIA and HKH (figure 5) show a greater b-value for KIA $(\sim 1.55$, figure $5 \mathrm{~b})$ as compared to $\mathrm{HPK}(\sim 1.15$, figure $5 \mathrm{a})$ and $\mathrm{HKH}(\sim 1.06$, figure $5 \mathrm{c})$. The 


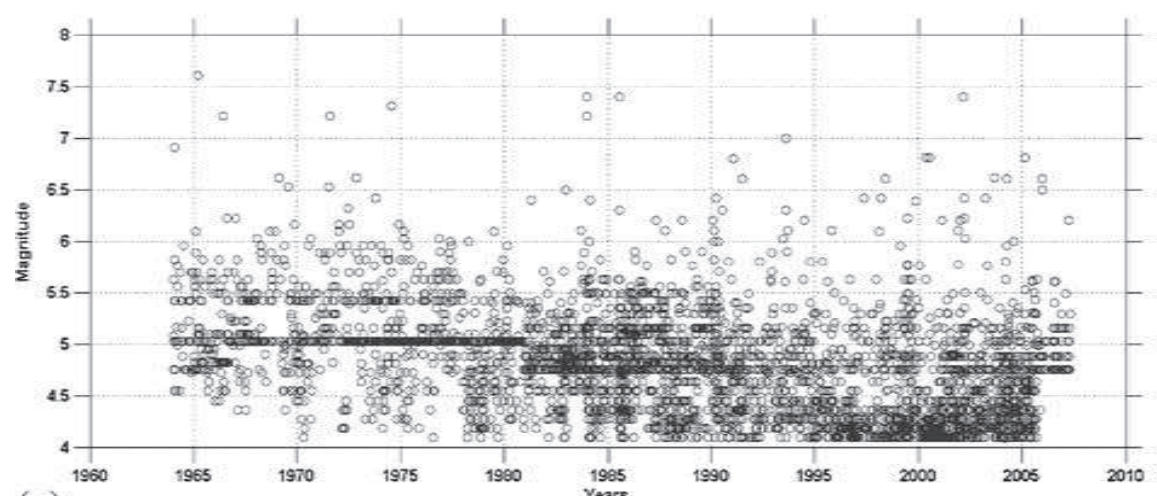

(a)

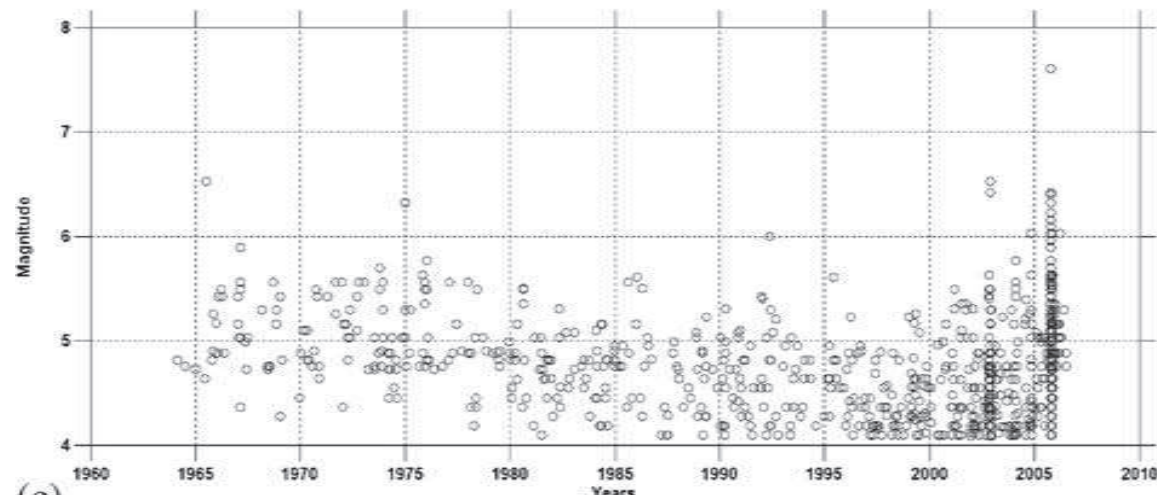

(c)

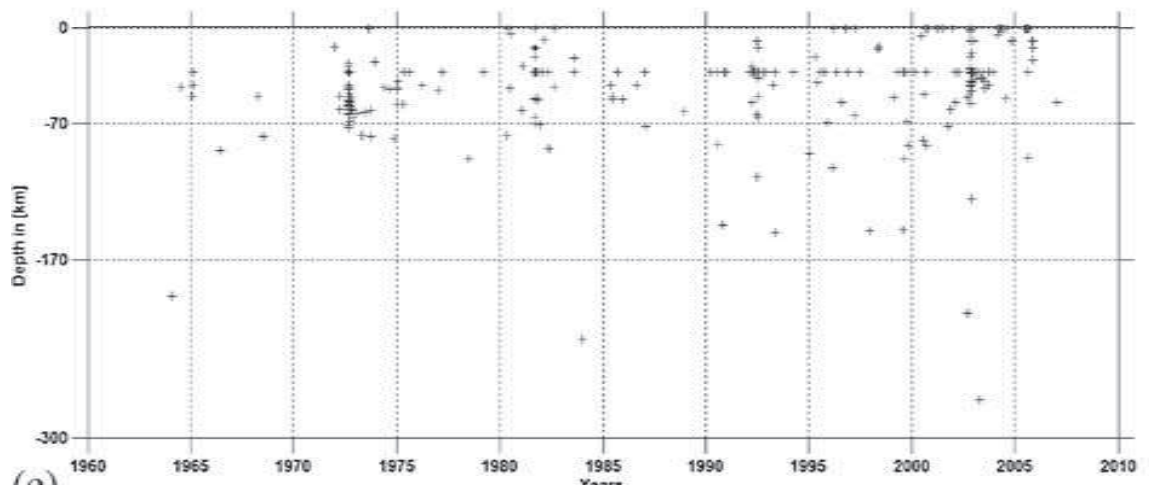

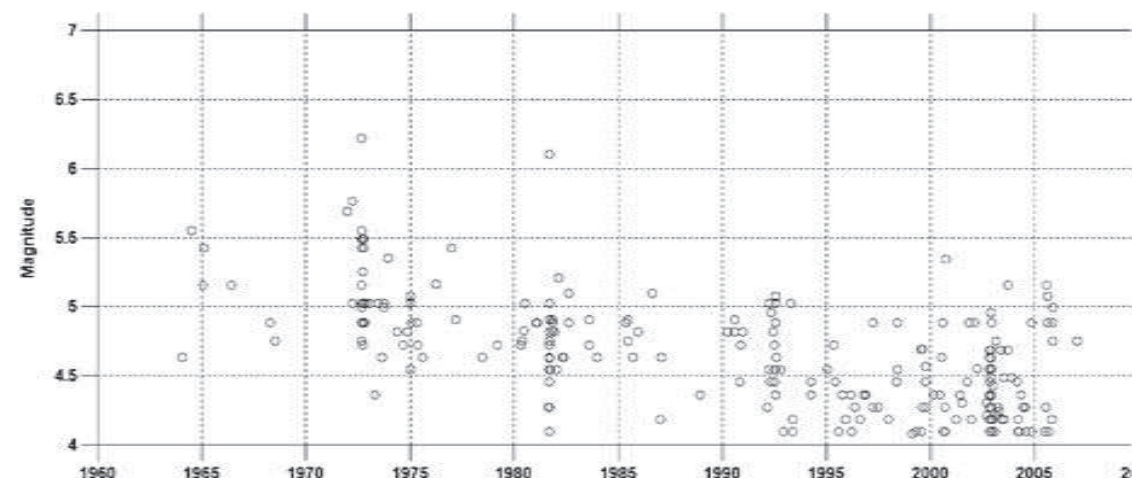

(b)
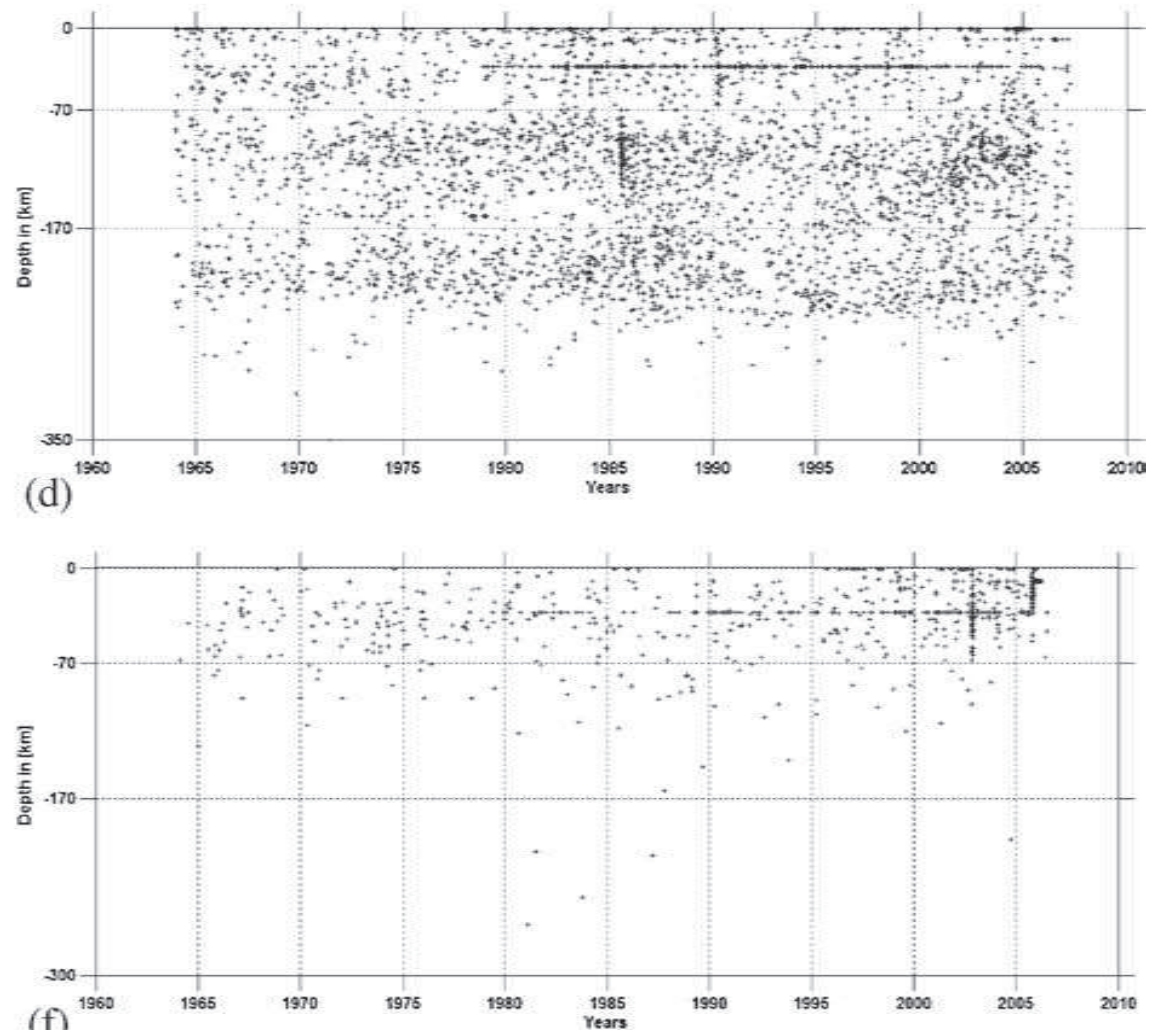

(f)

Figure 4. Time series plots of (a) time-magnitude plot of HPK, (b) time-magnitude plot of KIA, (c) time-magnitude plot of HKH, (d) time-depth plot of HPK, (e) time-depth plot of KIA, and (f) time-depth plot of HKH. 

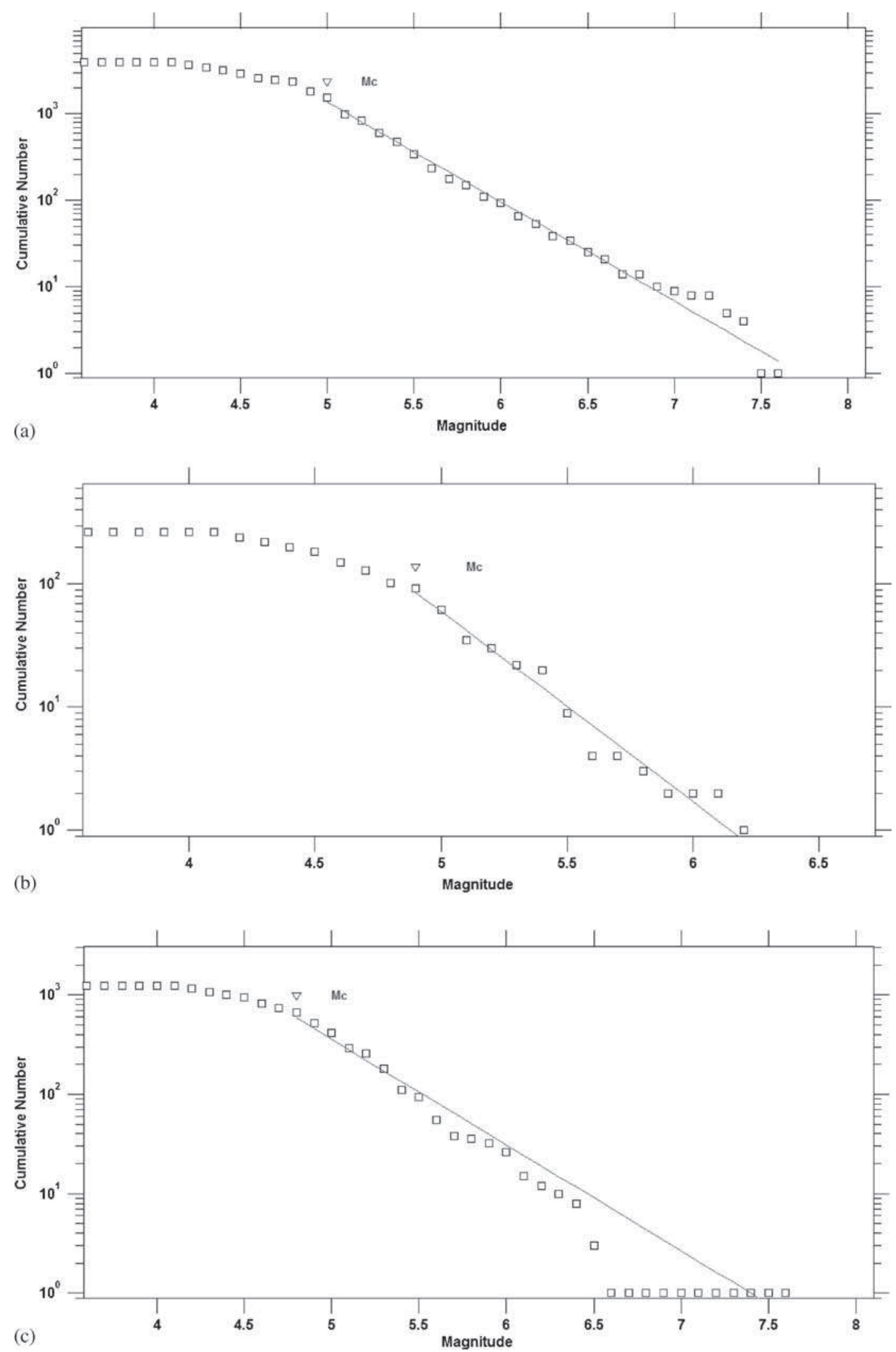

Figure 5. Maximum likelihood estimation for $(\mathbf{a}) \mathrm{HPK}(\mathrm{Mc}=5.0, \mathrm{~b}=1.15 \pm 0.03$, a-value $=8.89),(\mathbf{b}) \mathrm{KIA}(\mathrm{Mc}=4.9, \mathrm{~b}=1.55 \pm$ 0.2 , a-value $=9.51)$, and $(\mathbf{c}) \mathrm{HKH}(\mathrm{Mc}=4.8, \mathrm{~b}=1.06 \pm 0.04$, a-value $=7.88)$.

existing work of Riad et al. (1988) on b-value for Pakistan ( 0.65) suggests a low b-value as compared to the values computed in this study.
This difference in b-value can be attributed to the fact that Riad et al. (1988) use earthquake data for the period 1900-1983 (longer time period than 

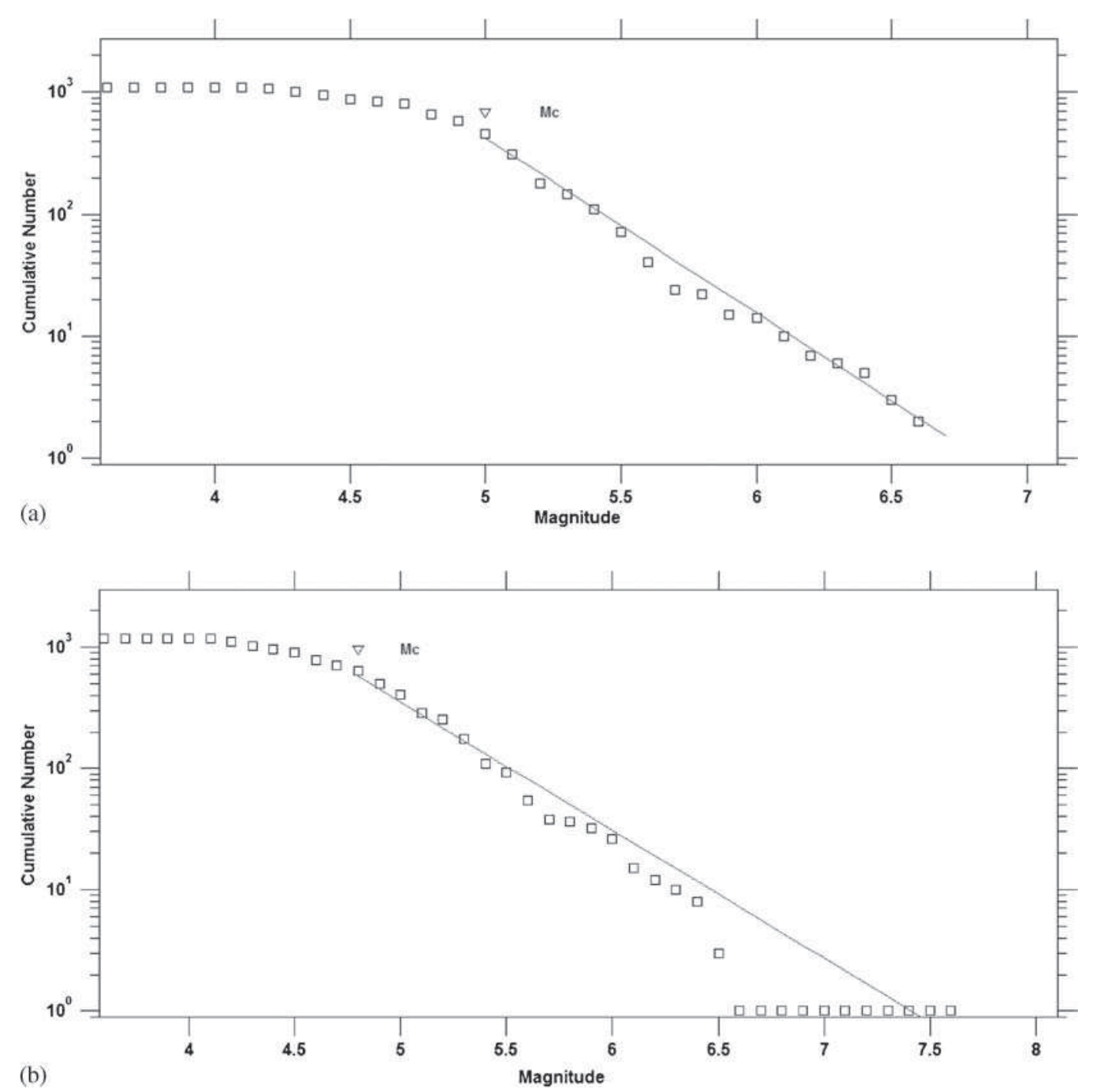

Figure 6. Maximum likelihood estimation for shallow earthquakes in (a) HPK $(\mathrm{Mc}=5.0, \mathrm{~b}=1.44 \pm 0.06, \mathrm{a}$-value $=9.8)$ and (b) $\mathrm{HKH}(\mathrm{Mc}=4.8, \mathrm{~b}=1.05 \pm 0.04$, a-value $=7.82)$.

the current study) with a much larger study area (Middle East including Pakistan). It has been shown that in general the b-value of $\sim 1$ vary from time to time in the same region (Frohlich and Davis 1993; Olsson 1999). In addition, we look at the b-values for the HPK and HKH without incorporating intermediate and deep focus earthquakes $(>70 \mathrm{~km})$. The b-values for these areas of shallow seismic activity are shown in figure 6 . The bvalue of HPK increases from 1.15 to 1.44 (figure 6a), while the same decreases in $\mathrm{HKH}$ from 1.06 to 1.05 (figure $6 \mathrm{~b}$ ). This is due to exclusion of concentration of large dataset of intermediate and deep focus earthquakes in the HPK (figure 4d). In contrast, $\mathrm{HKH}$ is dominated by shallow earthquakes in time depth plot (figure 4f). Figure 7 shows the b-value map of north Pakistan and its adjoining areas for earthquakes range in magnitude from 4.8 to $\leq 7.6$, between 1964 and
2007 in 20 cells with a size of $1^{\circ} \times 1^{\circ}$. Spatial bvalue results reveal that western parts of the MKT, MMT, extreme western part of MBT and HF have low and very low b-values. High and very high bvalues are concentrated in the eastern HPK and central parts of HPK, KIA and HKH. Furthermore, shifting of high to low b-value appears in and around the Hazara-Kashmir and Nanga ParbatHaramosh syntaxes. The b-value mapping clearly demonstrates the areas of high and low seismic potential in the investigated regions. These results can be compared with some existing tectonic and seismicity studies as well as with the past damaging earthquakes in the investigated regions as described above (Quittmeyer et al. 1979; Kazmi and Jan 1997; Ali and Khan 2004; Wheeler et al. 2005).

Very low b-value is found in the high seismicity zone of Hindukush region (approximately $200 \mathrm{~km}$ 


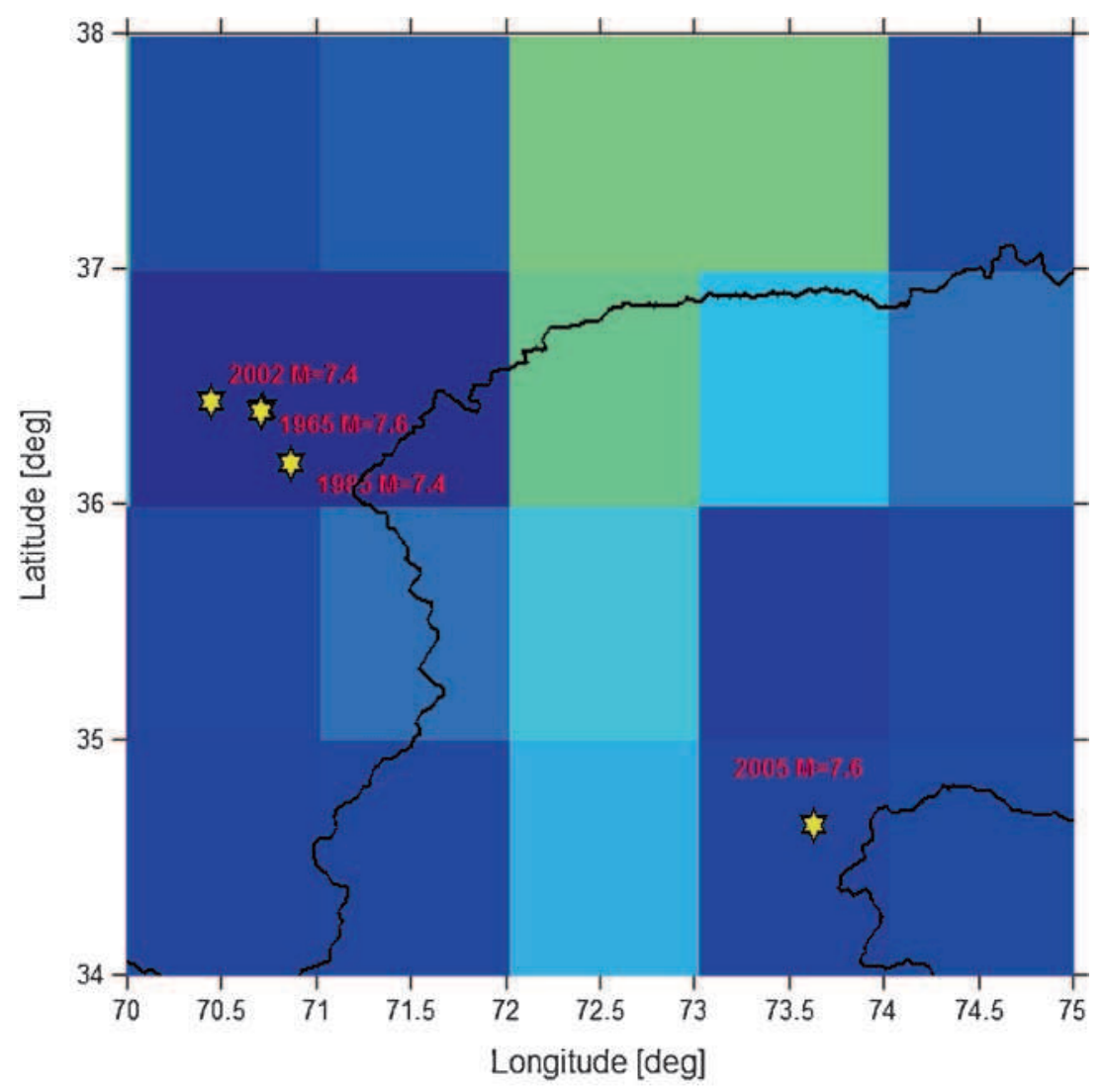

b-value:

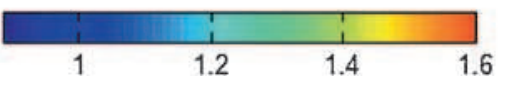

Figure 7. Map of b-values within investigated area displayed on cellular grid. Dark blue colours indicate lower b-values in and around Hindukush and Kashmir. The highest values of $\mathrm{b}$ in relatively low seismicity region of eastern part of MKT.

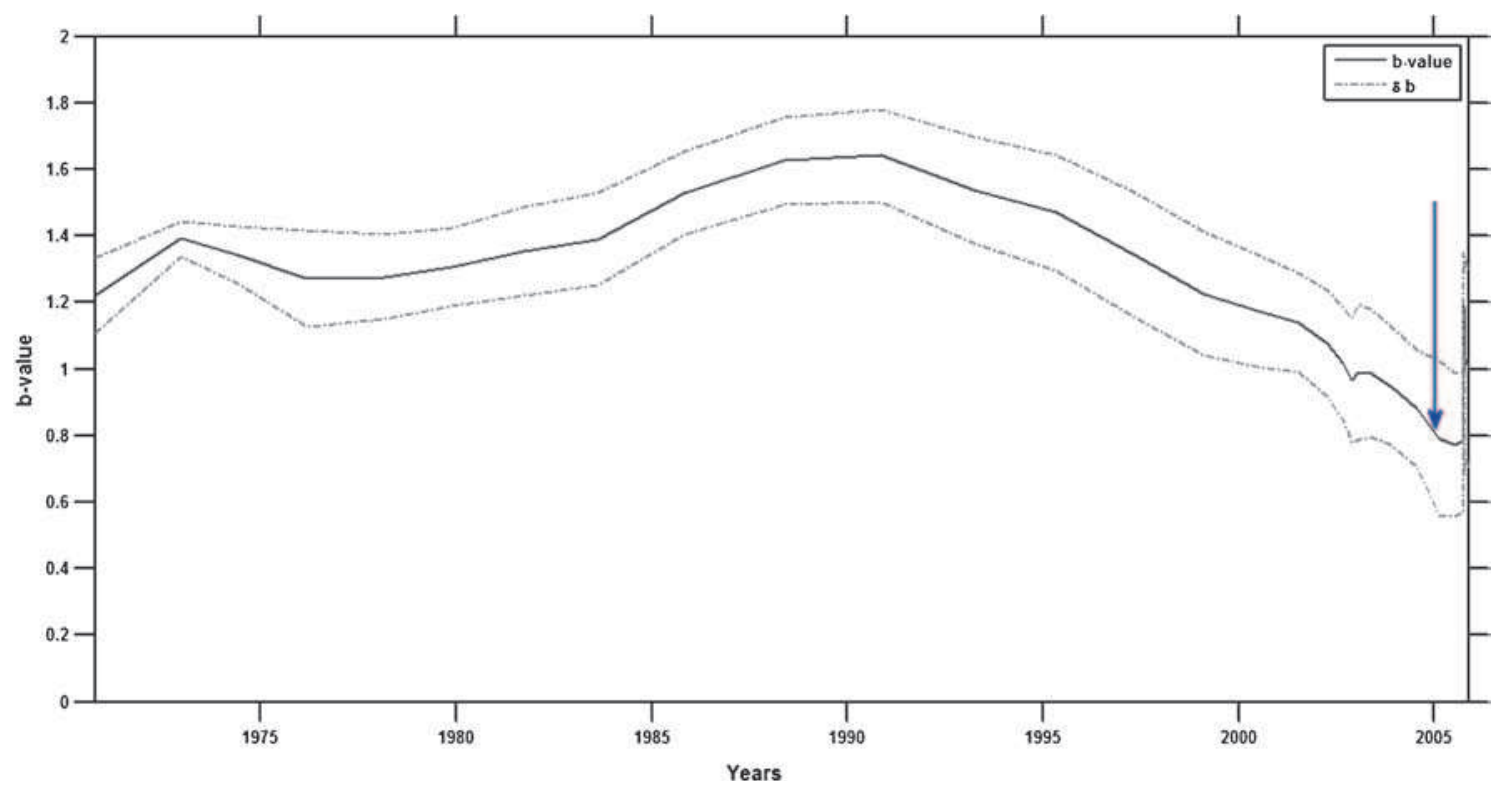

Figure 8. Temporal variation of seismic b-value (thick black line) in HKH from 1964 to 2007 and thick grey line is the standard deviation. Blue arrow indicates Kashmir earthquake (magnitude $=7.6$ ). 
northwest of Peshawar). Most of the earthquakes felt in Peshawar have their origin in Hindukush in Afghanistan or northern areas of Pakistan (Ali and Khan 2004). The intercontinental Hindukush mountain range hosts the most seismicity and one of the active zone of the world (Verma et al. 1980; Mahmood and Gloaguen 2012). Most seismic activity of shallow, intermediate and deep focussed earthquakes can be seen in and around the Hindukush range of Afghanistan and Pakistan (Wheeler et al. 2005). The Kohistan and the northwestern parts of Federally Administrated Northern Areas (FANA; $35^{\circ}-37^{\circ} \mathrm{N}, 72^{\circ}-75^{\circ} \mathrm{E}$ ) contributes to high seismic activities (Ambraseys et al. 1975; Quittmeyer and Jacob 1979; Jackson and Yielding 1983). The Nanga Parbat-Haramosh syntaxis, which tightly bended the MMT is also characterized by high seismicity. Peshawar, which is the capital city of the Khyber Pakhtunkhwa $(\mathrm{KPK})$, located in the west of the $\mathrm{HKH}$ domain is lying in relatively low seismicity zone. Historically, Peshawar is characterized by less damage in earthquake events. The survival of the historical and new buildings in Peshawar during earlier and 2005 (in particular) earthquakes suggest a low seismicity area (Ali and Khan 2004). However, Uniform Building Code (UBC) and GSHAP map indicate that Peshawar lies in the most earthquake hazardous zone. On the contrary, the results of this study imply that Islamabad, the capital of Pakistan lies in more seismic prone zone. The seismicity in the region is immanent from the collapse of Margalla towers during 2005 Kashmir earthquake, that killed 78 people. Similarly, Muzaffarabad is situated in the earthquake prone zone. Muzaffarabad, which lies in the core of the Hazara-Kashmir Syntaxis show lower bvalue than Islamabad and Peshawar. During 2005 Kashmir earthquake, the buildings located in eastern, western, central and apex regions of the Hazara-Kashmir Syntaxis were badly damaged (Burton et al. 2006). Therefore, the regions lying in the Hazara-Kashmir region show high seismicity (figure 2). The Hazara-Kashmir Syntaxis is dominated by active thrust faulting on eastern and western limbs, where the western limb is dominated by high seismicity (Ali et al. 2015).

The temporal plot of b-value in HKH indicated with the b-value in the black thick line, the standard deviation in the grey thick line and the blue arrow shows the devastating Kashmir earthquake $(\mathrm{Mw}=7.6$, figure 8$)$. The obtained result indicates that the b-value prominently decreased prior to Kashmir earthquake (October 8, 2005). Using regional and global catalogue, researchers have observed decrease in the b-value up to $50 \%$ (Molchan et al. 1999).

\section{Acknowledgements}

We acknowledge the research facilities provided by the National Centre of Excellence in Geology, University of Peshawar, Pakistan. We are thankful to the reviewers who provided valuable and useful comments.

\section{References}

Aki K 1965 Maximum lilkelihood estimate of b in the formula $\log N=a-b M$ and its confidence limits; Bull. Earthq. Res. Inst. 43 237-239.

Ali Q and Khan A N 2004 A critical review of the seismic risk zoning and development of design spectra for Peshawar and adjoining areas; 13th World Conference on Earthquake Engineering Vancouver, B.C., Canada, August 1-6, 2004, Paper No. 50.

Ali A, Faisal S, Rehman K, Khan S and Ullah N 2015 Tectonic imprints of the Hazara-Kashmir Syntaxis on the northwest Himalayan fold and thrust belt, north Pakistan; Arab. J. Geosci., doi: 10.1007/s12517-015-1874-8.

Ambraseys N N, Lensen G and Monifer A 1975 The Pattan earthquake of 28 December, 1974; UNESCO Publications.

Bender B 1983 Maximum likelihood estimation of b values for magnitude grouped data; Bull. Seismol. Soc. Am. 73(3) 831-851.

Burton P W 1990 Pathways to seismic hazard evaluation: Extreme and characteristic earthquakes in areas of low and high seismicity; Nat. Hazards (3) 275-291.

Burton P W, Xu Y, Qin C, Tselentis G A and Sokos E 2004 A catalogue of seismicity in Greece and the adjacent areas for the twentieth century; Tectonophys. 390 117-127.

Burton P W, Hainzl S and Lasocki S 2006 Spatiotemporal models of seismicity and earthquake occurrence; Spec. Issue Tectonophys. $\mathbf{4 2 3} 148 \mathrm{p}$.

Cao A and Gao S S 2002 Temporal variation of seismic bvalues beneath northeastern Japan island arc; Geophys. Res. Lett. 29(9) 48-1-48-3.

Damanik R, Andriansyah Putra H E and Zen M T 2010 Variations of b-values in the Indian Ocean - Australian plate subduction in south Java Sea; In: Proceedings of the Bali 2010 International Geosciences Conference and Exposition, Bali, Indonesia, pp. 19-22.

Dunbar P K, Patricia A L and Lowell S 1992 Catalog of significant earthquakes, including quantitative casualties and damage; National Oceanic and Atmospheric Administration, National Environment Satellite Data and Information Service, National Geophysical Data Center, Report SE-49, 320p.

Engdahl E R, Hilst R V and Buland R 1998 Global teleseismic earthquake relocation with improved travel times and procedures for depth determination; Bull. Seismol. Soc. Am. $88722-743$.

Faisal S, Larson K P, Cottle J M and Lamming J 2014 Building the Hindu Kush: Monazite records of terrane accretion, plutonism and the evolution of the HimalayaKarakoram-Tibet orogeny; Terra Nova 26 395-401.

Farrell J, Husen S and Smith R B 2009 Earthquake swarm and b-value characterization of the Yellowstone volcanotectonic system; J. Volcanol. Geotherm. Res. 188 260-276.

Frohlich C and Davis S D 1993 Teleseismic b-values or much ado about 1.0; J. Geophys. Res. 98(B1) 631-644.

Ghosh A, Newman A V, Thomas A M and Farmer G T 2008 Interface locking along the subduction megathrust 
from b-value mapping near Nicoya peninsula, Costa Rica; Geophys. Res. Lett., doi: 10.1029/2007GL031617.

Gutenberg B and Richter C 1944 Frequency of earthquakes in California; Bull. Seismol. Soc. Am. 34 185-188.

Jackson J and Yielding G 1983 The seismicity of Kohistan, Pakistan: Source studies of the Hamran (1972.9.3), Darel (1981.9.12) and Patan (1974.12.28) earthquakes; Tectonophys. 9 15-28.

Jafari M A 2013 Spatial distribution of seismicity parameters in the Persian Plateau; Earth Planets Space 65 863-869.

Johnston A C 1994 The earthquakes of stable continental regions; TR-102261-V1. Final report 1994 (5 volumes). Prepared for EPRI, Palo Alto, California, USA.

Kazmi A H 1979 Preliminary seismotectonic map of Pakistan (1:2000,000); Geol. Surv. Pakistan.

Kazmi A H and Jan M Q 1997 Geology and Tectonics of Pakistan; Graphic Publishers.

Kearey P and Vine J F 1990 Global Tectonics; Blackwell Scientific Publications.

Khan P K 2003 Stress state, seismicity and subduction geometry of the descending lithosphere below the Hindukush and Pamir; Gondwana Res. 6 867-877.

Khan P K and Chakraborty P P 2007 The seismic b-value and its correlation with Bouguer gravity anomaly over the Shillong Plateau area: Tectonic implications; J. Asian Earth Sci. 29 136-147.

Khan P K, Mohanty S and Mohanty M 2010 Geodynamic implications for the 8 October 2005 north Pakistan earthquake; Surv. Geophys., doi: 10.1007/s10712-009-9083-1.

Kondorskaya N V and Shebalin N V 1982 (Russian edn 1975) New catalogue of strong earthquakes in the USSR from ancient times through 1977 (corrected and updated according to 2nd edn); Report SE-31, World Data CentreA for Solid Earth Geophysics, Boulder, Colorado, USA, 608 p.

Korrat I M, Hussein H M, Marzouk I, Ibrahim M, AbdulFattah R and Hurukawa N 2006 Seismicity of the northernmost part of the Red Sea (1995-1999); Acta Geophys. 54(1) 33-49.

Mahmood A A and Gloaguen R 2012 Appraisal of active tectonics in Hindu Kush: Insights from DEM derived geomorphic indices and drainage analysis; Geoscience Frontiers 3(4) 407-428.

Main I 2000 Apparent breaks in scaling in the earthquake cumulative frequency-magnitude distribution: Fact or artifact? Bull. Seismol. Soc. Am. 90 86-97.

Marzocchi W and Sandri L 2003 A review and new insights on the estimation of the b-value and its uncertainty; Ann. Geophys. 46 1271-1282.

Molchan G M, Kronrod T L and Nekrasova A K 1999 Immediate foreshocks: Time variation of the b-value; Phys. Earth Planet. Inter. 111 229-240.

Nuannin P 2006 The potential of b-value variations as earthquake precursors for small and large events; Digital Comprehensive Summaries of Uppsala Dissertations from the Faculty of Science and Technology.

Olsson R 1999 An estimation of the maximum b-value in Gutenberg-Richter relation; Geodynamics 27 547-552.

Pacheco J F and Sykes L R 1992 Seismic moment catalog of large shallow earthquakes, 1900 to 1989; Bull. Seismol. Soc. Am. 82 1306-1349.

Peiris N, Rossetto T, Burton P and Mahmood S 2008 Kashmir Pakistan earthquake of 8 October 2005; A Field
Report by EEFIT, Earthquake Engineering Field Investigation Team, Institution of Structural Engineers, London, www.eefit.org.uk, ISBN: 978-1-906335-11-3, 119p.

Quittmeyer R L, Farah A and Jacob K H 1979 The seismicity of Pakistan and its relation to surface faults, Geodynamics of Pakistan; In: Geodynamics of Pakistan, Geol. Surv. Pakistan, pp. 271- 284.

Quittmeyer R C and Jacob K H 1979 Historical and modern seismicity of Pakistan, Afghanistan, northwestern India, and south-eastern Iran; Bull. Seismol. Soc. Am. 69 773823.

Rao B R and Rao P S 1984 Historical seismicity of peninsular India; Bull. Seismol. Soc. Am. 74 2519-2533.

Rehman K, Burton P W and Weatherill G A 2014 K-means cluster analysis and seismicity partitioning for Pakistan; J. Seismol. 18 401-419.

Riad S, Meyers H and Kisslinger C 1988 Historical seismograms and earthquakes of the world; Academic Press, pp. 321-334.

Sandri L and Marzocchi W 2007 A technical note on the bias in the estimation of the b-value and its uncertainty through the least squares technique; Ann. Geophys. 50 329-339.

Scordilis E M 2006 Empirical global relations converting $\mathrm{M}_{\mathrm{S}}$ and $\mathrm{M}_{\mathrm{b}}$ to moment magnitude; J. Seismol. 10 225-236.

Seeber L, Armbruster J and Farhatullah S 1980 Seismic activity at Terbela dam site and surrounding region; Geol. Bull. Univ. Peshawar 13 169-191.

Shi Y and Bolt B A 1982 The standard error of the magnitude-frequency b-value; Bull. Seismol. Soc. Am. 72 1677-1687.

Spassov E, Sinadinovski C and McCue K 2002 Spatial and temporal variation of seismicity across Australia; J. Balkan Geophys. Soc. 5(4) 115-122.

Treloar P J, Coward M P, Chambers A F, Izzat C N and Jackson K C 1992 Thrust geometries, interferences and rotations in the northwest Himalaya; In: Thrust tectonics (ed.) McClay K R (New York: Chapman and Hall), pp. 325-342.

Urbancic T I, Trifu C I, Long J M and Young R P 1992 Space-time correlations of b-values with stress release; Pure Appl. Geophys. 139 449-462.

Utsu T 1992 On seismicity; In: Report of the Joint Research Institute for Statistical Mathematics, Inst. Stat. Math. Tokyo 34 139-157.

Verma R K, Mukhopadhyay M and Bhanja A K 1980 Seismotectonics of the Hindukush and Baluchistan arc; Tectonophys. 66 301-322.

Wheeler B R, Bufe C G, Johnson M L, Dart R L and Norton G A 2005 Seismotectonic map of Afghanistan, with annotated bibliography; USGS Open File Report 2005-1264, United States Geological Surevey.

Wiemer S A 2001 Software package to analyze seismicity: ZMAP; Seismol. Res. Lett. 72 373-382.

Wiemer S and Wyss M 2002 Mapping spatial variability of the frequency-magnitude distribution of earthquakes; Adv. Geophys. 45 259-302.

Wyss M 1973 Towards a physical understanding of earthquake frequency distribution; Geophys. J. Roy. Astron. Soc. 31 341-359.

Zhang P, Yang Z, Gupta H K, Bhatia S C and Shedlock K M 1999 Global seismic hazard assessment program (GSHAP) in continental Asia; Annali di Geofisica 42(6) 1167-1189. 